\title{
Main Allergens Observed in Patients with Contact Dermatitis in a Brazilian Population Group
}

\author{
Zamir Calamita ${ }^{*}$, Ana Cristina Rizzo Alonso, Lorena Carla Oliveira da Costa and \\ Andrea Bronhara Pelá Calamita
}

Marília Medical School (FAMEMA), São Paulo, Brazil

\begin{abstract}
Background: The skin contact test or patch test is considered to be a fundamental tool for investigating allergic contact dermatitis (ACD). Better knowledge on the prevalence of allergens in the environment is a good strategy for enabling a better approach towards contact dermatitis (CD) cases.

Objective: The objective of the present study was to evaluate the prevalence of the main allergens of ACD in a population group in the interior of the state of São Paulo, Brazil.

Methods: The results from 368 patch tests on adult patients with CD were evaluated through a retrospective study under the supervision of the Discipline of Allergy and Clinical Immunopathology and the Discipline of Dermatology at the Marília Medical School.

Results: Mean age was $41.2\left( \pm \_17.2\right)$ years, with predomination of women $(71.5 \%)$. The majority of the patients $(91.3 \%)$ presented reactivity to at least one substance. Nickel sulfate and the perfume mix stood out as the most allergenic substances.

Conclusion: Among the variety of substances to be tested in an etiological investigation for $\mathrm{CD}$, perfumes and nickel are especially likely to be allergens in this population group.
\end{abstract}

Keywords: Allergic contact dermatitis, contact dermatitis, fragrance, nickel, perfume, patch test, skin test.

\section{INTRODUCTION}

Contact dermatitis $(\mathrm{CD})$ is a highly prevalent disease in the Brazilian environment and is responsible for a large proportion of occupational dermatosis and 4 to $7 \%$ of dermatological consultations [1].

It is caused by external agents that, when in contact with the skin, trigger an inflammatory reaction. It usually manifests clinically as eczema. The disease is classified as: primary-irritant contact dermatitis; allergic contact dermatitis; phototoxic contact dermatitis; or photoallergic contact dermatitis. Allergic contact dermatitis (ACD) is a consequence of an immune reaction mediated by $\mathrm{T}$ cells against substances named haptens, which generally have low molecular weight [2].

The skin contact test or patch test is the most efficient method for confirming the etiological diagnosis of ACD [3]. This test may be influenced by genetic factors and factors related to the ethnicity of the individuals analyzed [4]. Brazil has continental dimensions, important regional differences and highly diversified population characterized by a high rate of miscegenation between Caucasians, Amerindians and Africans.

*Address correspondence to this author at the Marília Medical School (FAMEMA), Vicente Ferreira, 648, Marília, São Paulo, Brazil; Tel: (55)14-34546548; E-mails: calamita@unimedmarilia.com.br, zcalamita@hotmail.com
The British guidelines for CD recommends the patch test for patients with persistent eczema-like eruptions, either when ACD is suspected or when it cannot be ruled out (evidence level II/ recommendation degree A), with sensitivity and specificity of between $70 \%$ and $80 \%$ [1].

\section{METHODS}

This was a retrospective study, in which the medical files of 368 adult patients with CD were evaluated. These patients were seen between August 2000 and January 2012 at the Allergy outpatient service of the Marília Medical School (FAMEMA) and at a private Allergy and Dermatology clinic in the municipality of Marilia, which is located in the interior of the state of São Paulo, Brazil. The study was supervised by the Discipline of Allergy and Clinical Immunopathology and the Discipline of Dermatology of FAMEMA. All the patients who underwent the patch test during this period were included in the study.

The following data were analyzed: age, sex, profession and history of other allergies. The patch tests results were first read 48 hours after the patches had been placed and then 72 hours after placement. The tested substances were listed in Table 1. They were produced by Alergofar (an allergen product laboratory), a Brazilian company registered with the National Sanitation Surveillance Agency (Agência Nacional de Vigilância Sanitária - ANVISA). The substances were applied to the patient's back by means of rectangular patches made of hypoallergenic adhesive tape with filter paper disks 
of area $1.0 \mathrm{~cm}^{2}$, which were duly identified. The reading criteria used were adapted from those of the Brazilian Workgroup for Contact Dermatitis (Grupo Brasileiro de Estudo em Dermatite de Contato, GBEDC) [5]:

Negative: no reaction

Doubtful: poorly defined mild erythema

Weakly positive: defined erythema, infiltration and papules

Strongly positive: erythema, infiltration, papules and vesicles

Very strongly positive: erythema, infiltration, papules and coalescent vesicles forming blisters

The present study was approved by the Research Ethics Committee of FAMEMA.

\section{RESULTS}

The mean age found was $41.2\left( \pm \_17.2\right)$ years with a median of 38 years. The patients were predominantly female $(71.5 \%)$.

Regarding professional occupation, $22.3 \%$ worked in commerce, $16 \%$ were either housewives or worked as cleaners, $8.2 \%$ were teachers, $7.3 \%$ were healthcare professionals, $6.3 \%$ had retired, $5.7 \%$ were factory workers, $1.6 \%$ were policemen, $1.4 \%$ were farm workers, $0.5 \%$ worked in construction, $0.5 \%$ were hairdressers and the remaining $30.2 \%$ had other occupations.

The great majority of patients, i.e. 336 (91.3\%), demonstrated reactivity in the patch test, of whom $34.2 \%$ reacted to only one substance, while $57.1 \%$ reacted to two or more substances. In total, 1,097 reactions were detected, of which 108 were doubtful and 989 were positive. A mean of 2.94 or almost three positive substances was found for each reactive patient. Among the positive results, 212 were very strongly positive, 495 strongly positive and 282 weakly positive.

Regarding the substances tested, we observed that nickel sulfate was the most allergenic substance, followed by the perfume mix. Table 1 presents the percentages of allergenic reactions observed for each of the tested substances, along with their concentrations.

Regarding other allergies, $14.6 \%$ reported having rhinitis, $11.6 \%$ had a history of drug hypersensitivity, $6.2 \%$ reported having chronic hives and $3.8 \%$ had asthma. Only 16 patients out of the 368 evaluated had histories of atopic dermatitis $(0.04 \%)$.

\section{DISCUSSION}

Contact dermatitis is one of the main complaints within the specialties of allergy and dermatology. It is an important cause of morbidity, occupational incapacity and diminished quality of life for the people affected.

The importance of monitoring this condition is demonstrated by the fact that, every two years, the North American workgroup on contact dermatitis presents the results of their patch test assessments, carried out using a standardized series of allergens [6-8].
Table 1. Substances tested with their respective concentrations and sensitization percentages.

\begin{tabular}{|c|c|}
\hline $\begin{array}{c}\text { Substances and } \\
\text { Concentrations Tested }\end{array}$ & $\begin{array}{c}\text { Percentages } \\
\text { of Sensitization }\end{array}$ \\
\hline Nickel sulfate 5\%* & $36.70 \%$ \\
\hline Perfume mix $8 \% *$ & $27 \%$ \\
\hline Thimerosal $0.05 \% *$ & $23.60 \%$ \\
\hline Hydroquinone 1\%* & $14.10 \%$ \\
\hline Balsam of Peru $25 \% *$ & $12.20 \%$ \\
\hline Benzoic acid 5\%* & $11.90 \%$ \\
\hline PPD mix $0.4 \% *$ & $11.70 \%$ \\
\hline Imidazole derivatives $7 \% * / * *$ & $10.60 \%$ \\
\hline Paraben mix $15 \% *$ & $9.20 \%$ \\
\hline Potassium bichromate $0.5 \% *$ & $8.20 \%$ \\
\hline Promethazine 1\%* & $7 \%$ \\
\hline Carba mix 3\%* & $6.80 \%$ \\
\hline Colophony $20 \% *$ & $6.20 \%$ \\
\hline Thiuram mix $1 \% *$ & $5.70 \%$ \\
\hline Benzocaine 5\%* & $5.40 \%$ \\
\hline Epoxy resin $1 \% *$ & $5.20 \%$ \\
\hline Neomycin $20 \% *$ & $4.60 \%$ \\
\hline Aniline $1 \% *$ & $4 \%$ \\
\hline Toluene $0.5 \% *$ & $4 \%$ \\
\hline Ethylenediamine $1 \% *$ & $3.50 \%$ \\
\hline Lanolin 30\%* & $3.50 \%$ \\
\hline Turpentine $10 \% *$ & $3.20 \%$ \\
\hline Mercuric chloride $0.1 \% *$ & $3 \%$ \\
\hline Chloramphenicol 2\%* & $3 \%$ \\
\hline Latex in natura & $3 \%$ \\
\hline Sulfanilamide $5 \% *$ & $3 \%$ \\
\hline 4-tert-butylphenol 1\%* & $2.70 \%$ \\
\hline Imidazolidinyl urea $2 \%$ & $2.70 \%$ \\
\hline Kathon CG $0.01 \% * / * * *$ & $2.70 \%$ \\
\hline Nitrofurazone $1 \%$ & $2.40 \%$ \\
\hline Vioform $6 \% *$ & $2.40 \%$ \\
\hline Sodium lauryl sulfate $2 \% * * * *$ & $2.20 \%$ \\
\hline Quinoline mix 6\% * & $2.20 \%$ \\
\hline Propylene glycol 5\%* & $1.90 \%$ \\
\hline Anthraquinone 2\%* & $1.60 \%$ \\
\hline Para-aminobenzoic acid $10 \% *$ & $1.60 \%$ \\
\hline Boric acid $1 \% * * * *$ & $1.40 \%$ \\
\hline Cobalt chloride $2 \% *$ & $1.40 \%$ \\
\hline Triclosan $1 \% *$ & $1.40 \%$ \\
\hline Quaternium-15 0.5\%* & $1 \%$ \\
\hline Mercapto mix $2 \% *$ & $0.80 \%$ \\
\hline Formaldehyde $2 \% * * * *$ & $0.50 \%$ \\
\hline Sodium hypochlorite $5 \% * * * *$ & $0.50 \%$ \\
\hline Eosin $50 \% *$ & $0.30 \%$ \\
\hline Polyethylene glycol 4\%* & $0.30 \%$ \\
\hline Chlorhexidene $1 \% * * * *$ & $0 \%$ \\
\hline Phenol $0.5 \% * * * *$ & $0 \%$ \\
\hline Pyrogallol $1 \% * * * *$ & $0 \%$ \\
\hline Resorcinol 1\%* & $0 \%$ \\
\hline
\end{tabular}

*Diluted in petrolatum ** miconazole, ketoconazole and tioconazole, in equal parts ***mixture of methylchloroisothiazolinone and methylisothiazolinone ****Diluted in water. 
The present study involved 49 substances that are potentially present in the Brazilian environment, thus encompassing more than 30 substances from the standard set established by the GBEDC [5], which therefore enables broader evaluation of probable allergens.

Demographically, as observed in the present study, other Brazilian studies also found greater predominance among young female adults $[5,9,10]$.

Test results that were positive for at least one substance were observed among $91.3 \%$ of the patients evaluated, while other Brazilian studies found this result among $62 \%$ to $62.8 \%[5,6]$. The higher percentage of reactors in this study probably occurred because the population studied had a high degree of suspicion to present contact dermatitis. This happened because the group was composed of selected patients in a specialized clinic in allergy area.

The main allergen found was nickel sulfate (36.7\%), and this was similar to the findings from other Brazilian studies: (25.1\%) [5] and 31,4\% [9], and foreign studies [6-8, 11]. The second most prevalent allergen in the present study was the perfume mix (27\%), as also observed in a study carried out in Germany [11], although different to two other Brazilian studies $[5,9]$. These studies found that thimerosal was the second most prevalent substance, while in the present study this substance was the third most prevalent. The fact that $87.3 \%$ of the tests in the present investigation were positive for these substances is highly relevant. Moreover, among the ten main positive substances found in Brazilian studies, four match those found in the present assessment: nickel, thimerosal, perfume mix and potassium bichromate $[5,9]$.

Nickel contact dermatitis (NCD) gives rise to important loss of quality of life and can lead to occupational damage, as well as significant expense on healthcare. Although such conditions may be related to occupational diseases, most are in fact related to non-occupational cases [12].

NCD occurs when metallic objects are in contact with the skin, especially when they are corroded by sweat, saliva or other body fluids, thereby releasing nickel ions that act like hapten and induce sensitization.

The amount of exposure to nickel according to area can be quantified in $\mu \mathrm{g} / \mathrm{cm}^{2}$ and may vary depending on the amount of nickel released and the duration of contact. European legislation established limits for the nickel concentration and the amount released from products that are in touch with the skin, which were $0.05 \%$ and 0.5 $\mu \mathrm{g} / \mathrm{cm}^{2} /$ week, respectively $[12,13]$. Subsequently, decreased prevalence of nickel allergy in Denmark and Germany was observed [12]. Stainless steel and gold usually release less than $0.5 \mu \mathrm{g} / \mathrm{cm}^{2} /$ week, while other materials covered by nickel generally release more than this amount and are therefore important triggers and causes of worsening of NCD among previously sensitized patients.

Earrings are one of the main triggers of NCD, particularly among women. Moreover, in addition to the ears, the neck and eyelids are frequently areas of sensitization due to the use of necklaces and through polished fingernails that come into contact with the region of the eyes and neck. Nickel can also be found in makeup products, hair dyes and various metallic objects such as bracelets, buttons, clothes, cloth dyes, coins, etc.

Regarding occupational exposure, nickel is also a central issue. A Brazilian study demonstrated that occupational exposure had occurred among 39\% of the 404 patients with positive reactions to any of the three metals that were studied (nickel, cobalt and chrome). Nickel was shown to be the most allergenic among the three, either alone or associated with others [14]. A British study observed nickel sensitization in $12 \%$ of the 1,190 cases of occupational dermatitis that were evaluated [15]. Sensitization usually occurs through non-occupational exposure, which worsens after exposure at work. However, occasionally, sensitization occurs at the workplace, especially in humid environments where there is contact with nickel [13]. In general, these workers develop chronic eczema, especially on their hands.

Regarding perfumes, these are known to be the most common cause of contact dermatitis due to cosmetics [16]. The composition of the perfume mix consisted of cinnamic aldehyde, cinnamic alcohol, alpha-amyl cinnamic alcohol, geraniol, eugenol, isoeugenol, oakmoss absolute and hydroxycitronellal. Reactions can occur through contact with perfumes, cosmetics, soaps, detergents, medications, papers, hygienic wipes or even the perfumed items from other people.

Contact dermatitis due to perfumes may occur in a generalized or localized manner, such as on the hands, face, neck, trunk, axillae and legs, and may or may not be associated with occupational risk [17]. Regarding occupational issues, dermatitis has been especially associated with physical therapists, masseuses, nurses for elderly people, etc.

A multicenter study encompassing Europe, the United States and Japan, which had the objective of identifying possible new chemical components (other fragrances) for researching with regard to contact dermatitis due to perfumes, showed that $76 \%$ of the individuals evaluated presented a reaction to the perfume mix. Allergy due to perfumes preferentially affected women, on their faces and hands, and many patients reporting a personal history of rhinitis, asthma or atopic dermatitis. Regarding the other ingredients that were tested, it was found that $60 \%$ to $70 \%$ of the patients who were allergic to perfumes reacted to the total set of fragrances of the mix studied [18].

Use of perfumes in areas previously injured by eczema seems to favor new sensitizations. Moreover, if the fragrances are contained within mixtures with irritants such as soaps, detergents or other possible primary irritants, these could act as coadjuvants for precipitating the allergy. This may also happen through use of deodorants or other perfumes in recently depilated and irritated areas, such as the axillae [19].

In conclusion, there was a high positivity rate among the patients tested. Nickel sulfate and the perfume mix acted as the most sensitizing substances, corresponding together to $63.7 \%$ of the positive tests. 


\section{CONFLICT OF INTEREST}

The authors confirm that this article content has no conflict of interest.

\section{ACKNOWLEDGEMENTS}

Declared none.

\section{REFERENCES}

[1] Bourke J, Coulson I, English J. Guidelines for the management of contact dermatitis: an update. Br J Dermatol 2009; 160: 946-54.

[2] Martins LEAM, Reis VMS. Imunopatologia da dermatite de contato alérgica. An Bras Dermatol 2011; 86(3): 419-33.

[3] Duarte I, Lazzarini R, Buense R, Pires MC. Dermatite de contato. An Bras Dermatol 2000; 75(5): 529-48.

[4] Deleo VA, Taylor SC, Belsito DV, et al. The effect of race and ethnicity on patch test results. J Am Acad Dermatol 2002; 46(Suppl 2): S107-12.

[5] Grupo Brasileiro de Estudo em Dermatite de Contato; Sociedade Brasileira de Dermatologia. Departamento Especializado de Alergia. Estudo multicêntrico para elaboração de uma bateriapadrão brasileira de teste de contato. An Bras Dermatol 2000; 75(2): 147-56.

[6] Zug KA, Warshaw EM, Fowler JF Jr, et al. Patch-test results of the North American Contact Dermatitis Group 2005-2006. Dermatitis 2009; 20(3): 149-60

[7] Fransway AF, Zug KA, Belsito DV, et al. North American Contact Dermatitis Group patch test results for 2007-2008. Dermatitis 2013; 24(1): 10-21.

[8] Warshaw EM, Belsito DV, Taylor JS, et al. North American Contact Dermatitis Group patch test results: 2009 to 2010. Dermatitis 2013; 24(2): 50-9.
[9] Rodrigues DF, Neves DR, Pinto JM, Alves MFF, Fulgêncio ACF. Results of patch-tests from Santa Casa de Belo Horizonte Dermatology Clinic, Belo Horizonte, Brazil, from 2003 to 2010. An Bras Dermatol 2012; 87(5): 800-3.

[10] Minelli L, Swenson AM. Estudo de 70 casos de eczema de contato: alérgenos observados. Rev Bras Alerg Imunopatol 1997; 20(5): 173-8.

[11] Schäfer T, Böhler E, Ruhdorfer S, et al. Epidemiology of contact allergy in adults. Allergy 2001; 56: 1192-6.

[12] Torres F, Graças M, Melo M, Tosti A. Management of contact dermatitis due to nickel allergy: an update. Clin Cosmet Investig Dermatol 2009; 2: 39-48.

[13] Kim YY, Kim MY, Park YM, Kim HO, Koh CS, Lee HK. Evaluating the nickel content in metal alloys and the threshold for nickel-induced allergic contact dermatitis. J Korean Med Sci 2008; 23: 315-9.

[14] Duarte I, Amorim JR, Perázzio EF, Junior RS. Metal contact dermatitis: prevalence of sensitization to nickel, cobalt and chromium. An Bras Dermatol 2005; 80(2): 137-42.

[15] Shum KW, Meyer JD, Chen Y, Cherry N, Gawkrodger DJ Occupational contact dermatitis to nickel: experience of the British dermatologists (EPIDERM) and occupational physicians (OPRA) surveillance schemes. Occup Environ Med 2003; 60: 954-7.

[16] Scheinman PL. Allergic contact dermatitis to fragrance: a review. Am J Contact Dermat 1996; 7(2): 65-76

[17] Uter W, Schnuch A, Geier J, Pfahlberg A, Gefeller O. Association between occupation and contact allergy to the fragrance mix: a multifactorial analysis of national surveillance data. Occup Environ Med 2001; 58: 392-8.

[18] Larsen W, Nakayama H, Fischer T, et al. Fragrance contact dermatitis - a worldwide multicenter investigation (part III). Contact Dermatitis 2002; 46(3): 141-4

[19] Guin JD, Berry VK. Perfume sensitivity in adult females: a study of contact sensitivity to a perfume mix in two groups of student nurses. J Am Acad Dermatol 1980; 3: 299-302.

This is an open access article licensed under the terms of the Creative Commons Attribution Non-Commercial License (http://creativecommons.org/licenses/by-nc/ 3.0/) which permits unrestricted, non-commercial use, distribution and reproduction in any medium, provided the work is properly cited. 